\title{
Cytology as a guide to the presence of chlamydial inclusions in Giemsa-stained conjunctival smears in severe endemic trachoma
}

\author{
C. YONEDA, C. R. DAWSON, T. DAGHFOUU, I. HOSHIWARA, P. JONES, \\ M. MESSADI, AND J. SGHAGHTER \\ From the Francis I. Proctor Foundation for Research in Ophthalmology, University of California, San Francisco; \\ l'Institut d'Ophtalmologie, Tunis, Tunisia; the George Williams Hooper Foundation, University of California, \\ San Francisco; and the Division of Indian Health, U.S. Public Health Service
}

The Giemsa stain was first used to demonstrate the causative agent of trachoma by Halberstaedter and von Prowazek (1907) who found inclusions in conjunctival scrapings from an experimentally infected orang-utan. Since then there have been few easily applied alternatives to this method of demonstrating the trachoma agent. Iodine staining has been used by some investigators but is probably less sensitive and may be non-specific (Dawson and Schachter, 1967; Sowa, Collier, and Sowa, 1971). Fluorescent antibody (FA) staining methods have been shown to be very sensitive but are essentially research tools requiring experienced investigators and do not allow detailed cytological analysis of the slides (Schachter, Dawson, Balas, and Jones, 1970). Isolation methods to detect the trachoma agent by either egg isolation or tissue cultures are performed in a few specialized laboratories (Schachter, 1970; Gordon, Harper, Quan, Treharne, Dwyer, and Garland, 1969). Thus the detection of trachoma agent by Giemsa staining is still a simple and definitive method for laboratory confirmation of clinical diagnosis in trachoma endemic areas where sophisticated technology is unlikely to be available.

Several investigators have pointed out that conjunctival scrapings from patients with trachoma regularly contain certain cellular elements which can be helpful in the diagnosis of this disease (Thygeson, 1946; Hardy, Surman, and Howarth, 1967). This report reviews our findings on the cytology and presence of inclusions in Giemsa-stained conjunctival scrapings collected in a community with severe endemic trachoma. In this study, certain cytological patterns appeared to be associated regularly with

Address for reprints: Dr. Chandler Dawson, Francis I. Proctor Foundation, University of California, San Francisco, California 94143, U.S.A.

Supported in part by grants from the N.I.H.: EY.00427, EY.00186, AI.10193; and by PL.480 Grant 07-075 through the Health Services Administration, U.S. Public Health Service, Department of Health, Education and Welfare. inclusions and disease intensity. In addition, we compared the efficacy of Giemsa staining and FA staining in detecting inclusions in a group of matched smears.

\section{Material and methods}

(I) Conjunctival smears and Giemsa staining

After topical anaesthesia, conjunctival scrapings were taken from $15 \mathrm{I}$ children in a desert community in Southern Tunisia. All children had been diagnosed as having active trachoma in the autumn of 1970 when the first set of smears were taken. In a few cases the smears were repeated at 2- to 3-day intervals. Two subsequent sets of smears were obtained in March and June 197 I after antibiotic treatment in a controlled chemotherapy trial described elsewhere (Dawson, Dagfous, Messadi, Hoshiwara, Vastine, Yoneda and Schachter, 1974). The scrapings, obtained with a Kimura spatula from each eye, were spread thinly on a single glass slide, material from the two eyes being kept separate. The slides were allowed to dry in air for 15 minutes to 6 hours before being fixed for 5 minutes with absolute methyl alcohol at room temperature. The slides were transported to San Francisco without refrigeration. They were refixed in methanol before being stained for $\mathrm{I}$ hour with Giemsa stain buffered at $\mathrm{pH}$ $6 \cdot 8$, and rinsed briefly in 95 per cent. ethanol.

\section{(2) Fluorescent antibody staining}

In March and June, I97 I, smears for fluorescent antibody (FA) staining were taken at the same time as those for Giemsa. The staining and reading techniques for FAstained smears are described elsewhere (Schachter and others, 1970).

\section{(3) Microscopical examination}

The smear from each eye was examined microscopically for at least ro minutes. Smears with numerous inflammatory cells were usually examined for longer periods of time. At least thirty fields were examined with the $25 \times$ objective (200 $\times$ total magnification) and then another 
thirty fields with an oil immersion lens, usually $100 \times$ (80o $\times$ total magnification). Only smears estimated to have at least $\mathrm{I}, 000$ epithelial cells were considered adequate.

\section{(4) Microscopic features recorded}

Since the separation of epithelial cells appeared to be an important feature, this finding was recorded if present in more than half the low-power $(200 \times)$ fields examined. Among the other cellular features recorded in this study were:

(a) Polymorphonuclear neutrophils (PMNs);

(b) Small and medium-sized lymphocytes;

(c) Plasma cells;

(d) Blastoid cells and other stem cells;

(e) Leber cells (large macrophages with cytoplasmic debris);

(f) Multinucleated epithelial cells.

These cytological findings were graded on a scale of zero to 3 as follows:

o-Cytological feature not observed;

I-Feature present but found only rarely in the entire smear;

2-Feature not in every low-power field but easy to find; 3-For PMNs and lymphocytes, at least ten cells present in every low-power field; for other features at least one cell per low power field.

The results from each eye were tabulated separately.

\section{Results}

TRACHOMA INGLUSIONS AND PSEUDO-INCLUSIONS

In the smears examined in this study, typical chlamydial inclusions were found only in epithelial cells. Inclusions appeared as discrete masses in the cytoplasm consisting of particles ranging from the small $(300 \mathrm{~nm})$ red to purple staining elementary bodies to the larger (I $\mu$ ) dark blue staining initial bodies (Figs I, 2, 3). Elementary body inclusions were usually large and contained many particles (Figs I, 3). Initial body inclusions were smaller and contained fewer particles (Fig. 2). Not infrequently these two types of particles were found in the same inclusion (Fig. 3).

\section{PSEUDO-INGLUSIONS}

A number of structures were noted that are commonly confused with chlamydial inclusions and could be a source of error in the interpretation of smears. These include:

Pigment granules: Melanin granules were black or blackish-green in these Giemsa-stained smears (Figs 4 and 5). The individual particles were irregular in size but some approached the size of elementary bodies. Clumps of melanin granules rarely formed a close-packed cap over the nucleus of the cell closely resembling a trachoma inclusion (Fig. 5). Cosmetic particles are also found occasionally in epithelial cells.

Nuclear extrusions appeared in the cytoplasm as irregular masses attached to the nucleus (Fig. 6). These structures resembled the nucleus in colour and texture.

Goblet cells had granules which were less distinct than elementary bodies and lighter in colour. These cells were often clustered together (Fig. 7).

Eosinophilic granules appeared as individual or clustered granules on the surface of epithelial cells which sometimes resembled inclusions, but could be distinguished from inclusions by their colour, and by the presence of eosinophilic polymorphonuclear leucocytes and free granules (Fig. 8).

Bacteria: Since bacterial conjunctivitis is very common among children in this community, it was not surprising that various kinds of bacteria were identified in 444 ( 48 per cent.) of the 927 smears. Multiple types of bacteria in one smear were observed frequently. Among these bacteria were poorly-staining slender rods or coccobacilli (probably Haemophilus) which were found in 235 smears ( 53 per cent.) of bacterial positive smears (Fig. 9). Various forms of densely staining cocci were noted in 216 smears (49 per cent.) (Fig. 10), and Moruxella-like diplobacilli (Fig. II) in I 49 smears (35 per cent.). No intracellular diplococci were noted although pneumococcus-like forms were occasionally found to be covering epithelial cells. Epithelial parasitism by Koch-Weeks bacillus-like slender rods was also observed with relative frequency (Fig. 9). We have reported elsewhere that the major pathogen recovered in bacterial cultures from this group of children were Haemophilus sp. (Vastine, Dawson, Daghfous, Messadi, Hoshiwara, Yoneda, and Nataf (1974).

\section{PREVALENCE OF INCLUSIONS}

Among the 927 smears of individual eyes, 93 had typical trachoma inclusions in Giemsa-stained smears. Since many of the smears were obtained from patients with mild disease or after treatment, only a small number would be expected to have inclusions. The number of inclusions per positive smear ranged from $I$ to I I 7. Of these positive smears, 35 per cent. (33) had one inclusion, 40 per cent. (37) had two to nine inclusions, and 25 per cent. (23) had ten or more inclusions. The geometric mean number of inclusions per positive smear was three.

CORRELATION OF INDIVIDUAL GYTOLOGICAL FEATURES WITH INCLUSIONS

The presence of inclusions in slides with a single 
cytological feature is presented in Table I. The highest number of inclusion-positive smears was found in smears with the most common cytological featuresPMNs and separated epithelial cells. The other cytological findings occur less frequently and include fewer inclusion-positive smears.

The usefulness of single cytological findings as an indicator for inclusions in a slide is indicated as sensitivity (Table I) (Wilson and Jungner, 1968). Thus, while the separation of epithelial cells and presence of PMNs does not give a high yield of inclusions (2 I and 12.5 per cent.), these two signs are highly sensitive indicators, which could have been used as guides to detect all inclusion-positive smears in this series. The prevalence of inclusions was higher with the other cytological features (lymphocytes, plasma cells, blast cells, Leber cells), but the sensitivity of these features was much lower since they occurred less frequently.

In considering the specificity of each cytological feature (Wilson and Jungner, 1968), the presence of plasma cells, blast cells, Leber cells, and multinucleated cells have a high correlation with inclusions, but separated cells and PMNs are relatively nonspecific features for indicating inclusions (Table I). Thus, the highly sensitive indicators (e.g. PMNs) for inclusions have a relatively low specificity so that many slides would have to be examined to find all the inclusion-positive ones. Conversely, features with a specificity such as Leber cells have a low to moderate sensitivity since they occur less frequently, but are not always present in inclusion-positive smears.

The combination of these factors in relation to inclusion positivity is presented in Fig. 12 (p. 120) and Table II (p. I 22).

It is apparent that trachoma inclusions were found only in slides with both $3+$ PMNs and separated epithelial cells. However, when these two factors alone were present, only six of 233 smears ( 3 per cent.)

Table I Individual cytology features and inclusions: prevalence, sensitivity, and specificity

\begin{tabular}{|c|c|c|c|c|c|}
\hline \multirow[b]{2}{*}{ Sign } & & \multicolumn{2}{|c|}{ Prezialence } & Sensitivity & \multirow[b]{2}{*}{ Specificity* } \\
\hline & & \multicolumn{2}{|c|}{$\begin{array}{l}\text { No. of smears inclusion- } \\
\text { positive/No. with sign } \\
(\% \text { positive })\end{array}$} & $\begin{array}{l}\% \text { of smears with } \\
\text { sign among } 93 \text { inclusion- } \\
\text { positive smears }\end{array}$ & \\
\hline \multicolumn{6}{|l|}{ Separated cells } \\
\hline$(>50 \%)$ & & $93 / 449$ & $(2 I)$ & 100 & 0.462 \\
\hline Polys (PMN) & $\geqslant 3+$ & $93 / 743$ & $(12 \cdot 5)$ & 100 & $0 \cdot 109$ \\
\hline Lymphocytes & $\geqslant 3+$ & $82 / 190$ & (43) & 88 & 0.772 \\
\hline Plasma cells & $\geqslant 1+$ & $20 / 34$ & (59) & 22 & 0.959 \\
\hline Leber cells & $\geqslant 1+$ & I $1 / 20$ & （55） & 12 & $0 \cdot 976$ \\
\hline Blastoid cells & $\geqslant 2+$ & $54 / 83$ & $\left(6_{5}\right)$ & $5^{8}$ & $0 \cdot 900$ \\
\hline \multicolumn{6}{|c|}{ Multinucleated } \\
\hline cells & $\geqslant \mathrm{I}+$ & $49 / 149$ & （33） & 53 & 0.821 \\
\hline
\end{tabular}

$$
\text { * Specificity }=\frac{\text { Inclusion negative slides without sign }}{\text { All inclusion negative slides }}=\frac{\text { No. negative }}{834}
$$

FIGS I to II, I3 All twelve figures are Giemsa-stained conjunctival smears, the original photomicrographs were taken with a $100 \times / 0 i l$ immersion lens and the final magnification is $\mathrm{1}, 08 \mathrm{o} \times$.

FIG. I An elementary body inclusion in a conjunctival epithelial cell (lower right). In the upper left there is a macrophage (Leber cell) with numerous dark purple masses, probably PMN nuclei, in the poorly-defined cytoplasm.

FIG. $2 A$ cell with three initial body inclusions. The individual particles may be so tightly packed they cannot be distinguished. The individual initial bodies are smaller than most of the bacteria commonly found in the eye.

FIG. 3 An epithelial cell with multiple inclusions. Above and to the left of the nucleus an elementary body inclusion with both red and purple particles seems to be deforming the nucleus. A dense, probably less mature, elementary body inclusion lies adjacent and to the right of the nucleus. Several small initial body inclusions as well as individual elementary body particles are also present in the cytoplasm.

FIG. 4 Melanin granules in the cell form a "cap" over the nucleus suggesting a chlamydial inclusion. Melanin can be distinguished by its green-black colour in Giemsa-stained smears and by the occurrence of individual granules scattered throughout the cytoplasm of many adjacent cells.

FIG. 5 Melanin forming a tight "pseudo-inclusion" over the nucleus of an epithelial cell.

FIG. 6 Nuclear extrusions in the cytoplasm of epithelial cells. These extrusions are usually attached to and have the same colour and consistency as the nucleus. 

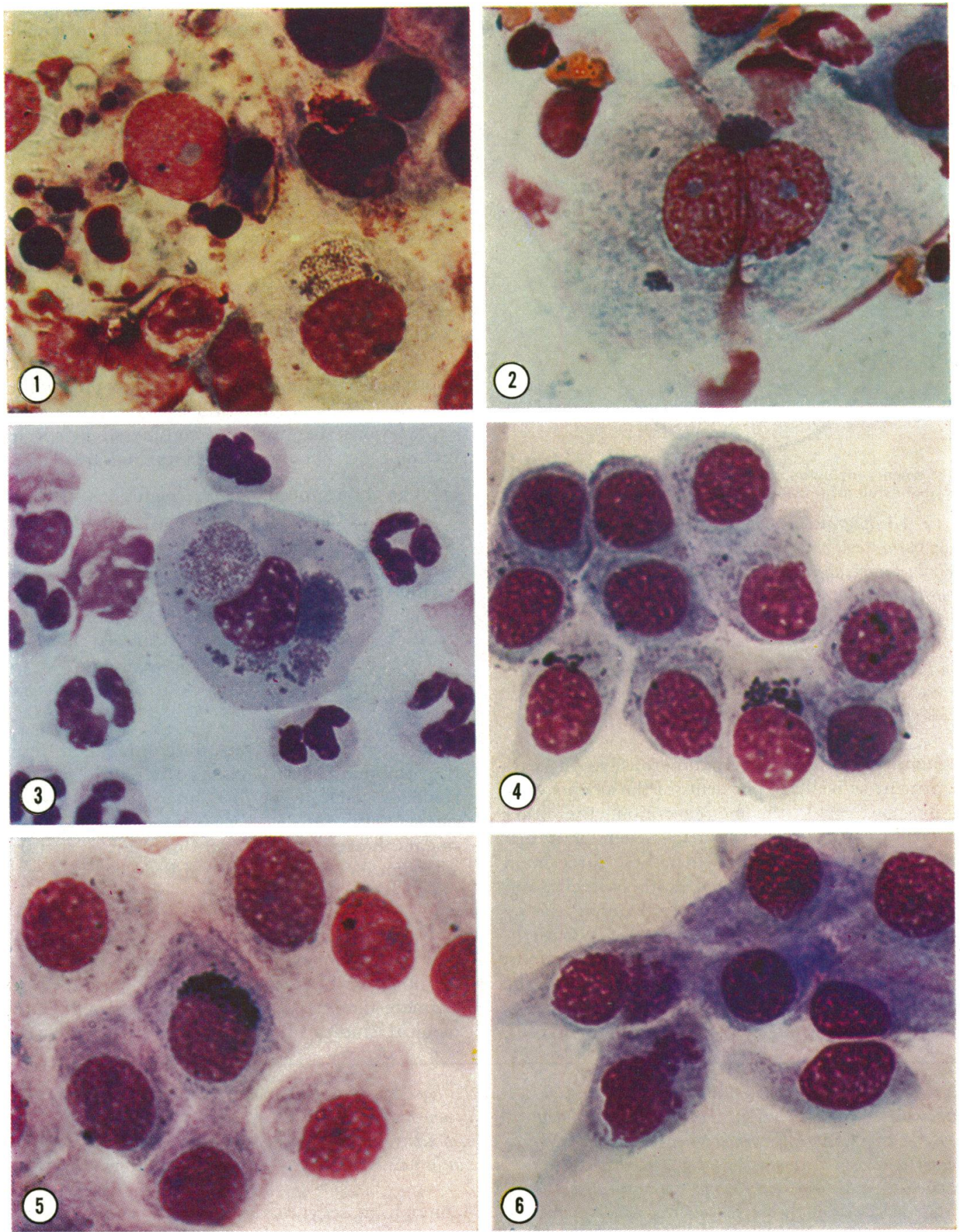


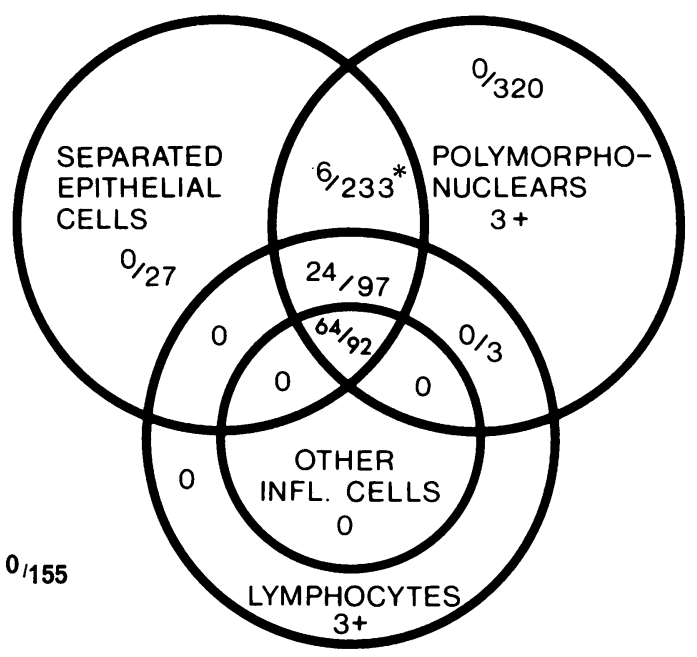

* No. of smears inclusion positive/no. of smears possessing designated cytological features (Giemsa stain)

FIG. I2 A diagram showing the association of inclusionpositive smears and chlamydial inclusions in Giemsa-stained smears. Inclusions were found only in smears with both separated epithelial cells and large numbers of PMNs. Smears with only these two features were inclusion-positive in 3 per cent.; if lymphocytes were present also, 25 per cent. had inclusions; if other inflammatory cells (blastoid cells, Leber cells, plasma cells, or multinucleated epithelial cells) were also present, 70 per cent. of smears were positive.

were inclusion-positive. When numerous lymphocytes were present as well, 25 per cent. of the smears were inclusion-positive. With one exception, the other cytological features, i.e. plasma, Leber, and $2+$ blastoid cells, occurred only when these three main elements $(3+$ PMNs, separated epithelial cells, and 3 + lymphocytes) were present, and among the 92 smears with all these signs 70 per cent. were inclusionpositive. Of the 23 smears with ten or more inclusions, twenty were found in this group of smears with all the cytological features.

The plasma cells, blastoid cells, other stem cells, and macrophages (Leber cells) probably originated in lymphoid germinal centres in the conjunctiva (Thygeson, 1946). Such lymphoid follicles are the hallmark of active trachoma and these rupture easily with the pressure of conjunctival scraping freeing these mononuclear cells.

\section{COMPARISON OF GIEMSA AND FA STAINING}

In March and June, I97 I, 527 matched smears were obtained for Giemsa and FA staining. The identification of inclusions by the two methods is compared in terms of cytology found in the Giemsa-stained smear of each pair (Table III). A total of 67 ( 13 per cent.) smears were inclusion-positive by one method or another. Inclusions were found by only one method in 37 pairs ( 13 by Giemsa and 24 by FA). Among the explanations that must be considered in specimens inclusion-positive by only one method are:

(I) The chance occurrence of inclusions in only one side of each pair, particularly those with few inclusions (less than five);

(2) The occurrence of inclusions which have lost the characteristic features necessary for diagnosis by Giemsa staining but which are still antigenic;

(3) Inclusions which have not stained by FA but would be Giemsa-positive (Sowa and others, I97 I);

(4) The presence of false positives in FA-stained smears.

The distribution of FA-positive smears in terms of the combinations of (Giemsa) cytological features corresponds generally to that found in Giemsa-positive smears. In fifteen FA-positive, Giemsa-negative smears, however, there were no unusual features or solely an increased number of PMNs.

\section{Discussion}

The detection of trachoma agent by laboratory methods can be used to diagnose individual cases, to estimate the infectious load of the agent in epidemiological studies or to monitor the effectiveness of

FIG. 7 Granules in goblet (mucin-producing) cells. The particles have a reddish-pink colour, and are seldom as distinct as chlamydial elementary bodies. The granules can occupy varying amounts of the cytoplasm.

FIG. 8 Eosinophilic polymorphonuclear leucocytes and free eosinophilic granules. The distinctive red colour and occurrence in leucocytes clearly distinguishes these from elementary bodies or inclusions. Both eosinophilic cells and free granules occur in large numbers in patients with atopic conjunctival reactions.

FIG. 9 Slender, slightly curved bacterial rods presumed to be Haemophilus aegyptius (or Koch-Weeks bacillus), on the surface of an epithelial cell. Both these $\mathrm{H}$. aegyptius-like forms and the $\mathrm{H}$. influenza-like (coccobacillary) bacteria stained pale blue quite unlike the deep blue of the other ocular bacteria. Epithelial parasitism such as this is a common feature with $\mathrm{H}$. aegyptius infections of the conjunctiva (Thygeson, 1946).

FI . IO Diplococci on a conjunctival epithelial cell. Such diplococci (probably pneumococci) occurred more frequently in the winter months (Vastine and others, 1974)

FIG. I I Large diplobacilli. These organisms are presumably Moraxella species.

FIG. I 3 Large diplococci in a scraping from an Egytian child with severe trachoma and Neisseria gonorrhoeae conjunctival infection proven by culture. 

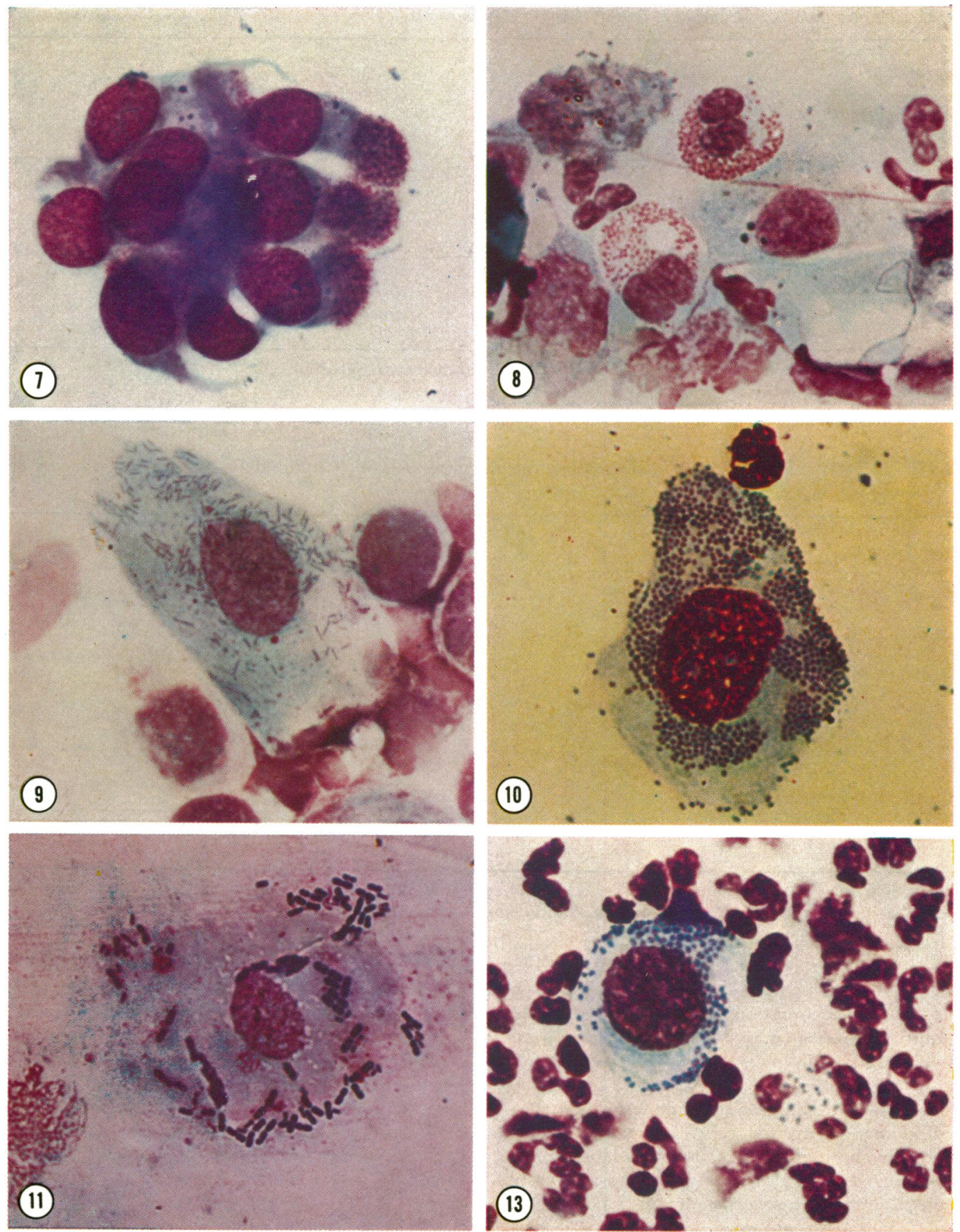
Table II Relative numbers of inclusions in 927 Giemsa-stained smears

Cytological features

\begin{tabular}{|c|c|c|c|}
\hline $\begin{array}{l}\text { Separated cell sheets } \\
(>50 \%)\end{array}$ & $\begin{array}{l}P M N s \\
3+\end{array}$ & $\begin{array}{l}\text { Lymphocytes } \\
3+\end{array}$ & Other ${ }^{1}$ \\
\hline- & - & - & - \\
\hline+ & - & - & - \\
\hline- & + & - & - \\
\hline+ & + & - & - \\
\hline- & + & + & - \\
\hline+ & + & + & - \\
\hline+ & + & + & + \\
\hline
\end{tabular}

No. positivel

Total number

(\% positive)

\begin{tabular}{l}
\hline $0 / 155$ \\
$0 / 27$ \\
$0 / 320$ \\
$6 / 233(3)$ \\
$0 / 3$ \\
$24 / 97(25)$ \\
$64 / 92(70)$
\end{tabular}

No. of inclusions ${ }^{2}$

\begin{tabular}{l}
\hline 0 \\
0 \\
0 \\
5 \\
0 \\
2 \\
4
\end{tabular}

(I) Plasrna cells, blastoid and stem cells, Leber cells, and multinucleated epithelial cells.

(2) Geometric mean number of inclusions per positive smear.

Table III Comparisons of Giemsa and immunoftuorescent staining in detecting Chlamydia inclusions in 527 matched smears from children in a trachoma therapy trial March and fune, 197 I

\begin{tabular}{|c|c|c|c|c|c|c|c|c|}
\hline \multicolumn{4}{|l|}{ Cytological features } & \multirow{2}{*}{$\begin{array}{l}\text { Total } \\
\text { number }\end{array}$} & \multicolumn{4}{|l|}{ Inclusions } \\
\hline $\begin{array}{l}\text { Separated epithelial } \\
\text { cells }\end{array}$ & $P M \mathcal{N S}_{s}$ & Lymphocytes & Other ${ }^{1}$ & & $\begin{array}{l}\text { Giemsa }+^{2} \\
F A+\end{array}$ & $\begin{array}{l}\text { Giemsa+ } \\
\text { FA- }\end{array}$ & $\begin{array}{l}\text { Giemsa- } \\
\text { FA+ }\end{array}$ & $\begin{array}{l}\text { Giemsa- } \\
F A-\end{array}$ \\
\hline- & - & - & - & $9 \mathrm{I}$ & o & o & 3 & 88 \\
\hline+ & - & - & - & 4 & 0 & 0 & o & 4 \\
\hline- & + & - & - & 228 & o & 0 & 12 & 216 \\
\hline+ & + & - & - & 120 & 3 & I & 3 & I 13 \\
\hline- & + & + & - & 2 & o & 0 & o & 2 \\
\hline+ & + & + & - & 35 & 7 & 2 & 5 & 21 \\
\hline+ & + & + & + & 47 & 20 & 10 & I & I 6 \\
\hline Total & & & & 527 & $30(5.7 \%)$ & I $3(2.5 \%)$ & $24(4.6 \%)$ & $460(87$ \\
\hline
\end{tabular}

(I) Plasma cells, blastoid and stem cells, Leber cells, and multinucleated epithelial cells

(2) Giemsa + indicates that inclusions were found in Giemsa-stained smears

treatment. Newer techniques, such as isolation in embryonated eggs, isolation in tissue culture cells, and immunofluorescent staining of smears, have been intensively studied in recent years (Schachter and others, 1970; Hardy and others, 1967; Darougar, Treharne, Dwyer, Kinnison, and Jones, 1971), but they all demand some degree of specialized competence so are limited to larger regional laboratories or to specialized research laboratories, and are rarely available in areas with severe endemic trachoma. In contrast, microscopical examination of Giemsastained smears can be carried out by most diagnostic microbiology laboratories and is a readily accessible technique.

Iodine staining to detect inclusions in conjunctival smears has been utilized extensively in studies of trachoma epidemiology and in vaccine studies on non-human primates (Sowa and others, I97I). The iodine method is less sensitive than either FA or Giemsa but in experienced hands is rapidly carried out (Dawson and Schachter, 1967). Moreover, the cytology cannot be evaluated in iodine-stained smears, so each smear must be examined with equal care. It does have the advantage, however, that very thick smears can be examined, thus increasing the yield to some degree (Sowa and others, 1971). Iodine staining then may be useful in certain situations.

The data presented in Fig. I and Table II suggest that, in searching for inclusions in Giemsa-stained smears, only those with separated epithelial cells and numerous PMNs need be considered as likely to have inclusions. Moreover, the chances of identifying inclusions increases sharply if lymphocytes and the other cytological features are present. These cytological features then can be used as a guide to select 
suspect smears for detailed microscopical examination. Thus a non-specialized laboratory should be able to search for inclusions in Giemsa-stained smears with some degree of confidence.

It has been suggested that the cytology of smears in endemic trachoma areas be used as an indicator of trachomatous involvement even if inclusions are not demonstrated (Hardy and others, 1967). We do not feel that the cytological pattern is a substitute for demonstrating the specific chlamydial inclusions in individual cases, in epidemiological studies, or in treatment studies. The individual cytological features described here occur in a number of conjunctival inflammations and cannot be considered specific for trachoma alone. For diagnostic purposes, however, the cytological findings may be considered suggestive of chlamydial infection in certain individual cases, e.g. the patient with subacute or chronic follicular conjunctivitis who has been partially treated with antibiotics.

In comparing the occurrence of inclusions in Giemsa and FA-stained smears, it is apparent that Giemsa staining gives a somewhat more conservative estimate of the prevalence of Chlamydia. We have noted elsewhere the close correlation of the intensity of conjunctival inflammation and occurrence of inclusions by either method (Dawson and others, in press). While more inclusion-positive smears were detected by the FA technique, these "excess" FA-positives seem to be related to intensity of disease and it is probable that they are not "false positives" but represent inclusions not recognizable in Giemsastained preparations.

One clear-cut advantage of Giemsa staining is that the original specimen (i.e. the stained smear) can be stored indefinitely and examined repeatedly without damage to the specimen. Thus these smears can also be sent to specialized laboratories for confirmation of suspected inclusions. FA smears, on the other hand, are best examined within 24 to 48 hours of staining. The more technically difficult isolation techniques of course yield strains of agent which can be further identified.

Large numbers of bacteria were noted in these smears taken from trachoma cases in this hyperendemic area where seasonal bacterial conjunctivitis is highly prevalent (Vastine and others, 1974). Since bacteria are rarely within the cytoplasm of epithelial cells and are usually much larger than the chlamydial initial or elementary body particles, they should not ordinarily be confused with chlamydial inclusions. Rarely cocci (particularly Neisseria) can be present in epithelial cells and can be confused in size and deep-blue staining characteristic with a single or double initial body (Fig. 13). Usually, however, the initial body inclusions consists of a cluster of smaller, very tightly packed particles (Fig. 2).

Some highly skilled cytologists have used the pres- ence of free elementary bodies to diagnose infection with the trachoma agent (Thygeson, 1946). Such free elementary bodies were noted in this study, but usually in slides that had many inclusions. Since the elementary bodies are at the limits of resolution of the light microscope (300 $\mathrm{nm}$ ) and smears often contain particulate debris of this size, we feel that the diagnosis of chlamydial infection should not be made on this basis alone.

Since the smears studied in this paper were obtained from patients with trachoma in an area where the disease is hyperendemic, the findings can be applied strictly only to this situation. We have found similar cytological findings in conjunctival scrapings from adults with oculo-genital Chlamydia infections (inclusion conjunctivitis). The findings cannot be applied to scrapings from the urethra in men or the cervix in women suspected of having genital chlamydial infection although there are many similarities. In newborns with chlamydial ophthalmia neonatorum, the cytology is less useful as a guide to the microbiological cause, but the large numbers of chlamydial inclusions in epithelial cells in such cases makes the specific diagnosis relatively easy.

\section{Summary}

Microscopical examination of 927 Giemsa-stained conjunctival smears from children with chronic trachoma in southern Tunisia showed 93 (10 per cent.) with typical trachoma (chlamydial) inclusions in epithelial cells. The accompanying cytological features were a useful indicator for inclusions. Inclusions were found only in slides with numerous polymorphonuclear neutrophils (PMNs) and separation of the epithelial cells. When these two features alone were present, 3 per cent. of the smears were inclusionpositive; when many lymphocytes were present also, 25 per cent. were inclusion positive; when other cytological features (plasma cells, macrophages, blastoid, and stem cells) were present as well, 70 per cent. of the smears were inclusion-positive. The occurrence of these sets of cytological features can be a useful guide for selecting smears for intensive examination for chlamydial inclusions. Immunofluorescent (FA) staining and Giemsa staining of 527 pairs of matched smears detected trachoma agent in 67 ( 13 per cent.); in thirty by both methods, in thirteen by Giemsa staining alone, and in 24 by FA alone. The examination of Giemsa-stained smears for chlamydial inclusions is a useful technique for the diagnosis of trachoma or inclusion conjunctivitis by laboratories that do not have the specialized facilities for the identification of these chlamydial infections by the technically more complex procedures of immunofluorescent staining or isolation in embryonated eggs or tissue cultures. 


\section{References}

Darougar, s., TREharne, J. D., DWYer, R. ST. C., Kinnison, J. R., and JONES, B. R. (1971) Brit. J. Ophthal., $55,59 \mathrm{I}$

DAWSON, C. R., DAGHFous, T., MesSAdi, M., HOShiWARA, I., VASTINE, D. W., YONEDA, C., and SGHAGHTER, J.

(1974) Arch. Ophthal. (Chicago), 92, 198

and schachter, J. (1967) Amer. F. Ophthal., 63, 1288

GORDON, F. B., HARPER, I. A., QUAN, A. L., TREHARNe, J. D., DWYER, R. ST. G., and GARLAND, J. D. (I969)

7. infect. Dis., 120, $45 \mathrm{I}$

HALBERSTAEDTER, K., and PROWAZEK, s. von (1907) Dtsch. med. Wschr., 33, I285

haRdy, D., SURman, P. G., and hOWARTh, w. H. (1967) Amer. F. Ophthal., 63, I 535

SGHACHTER, J. (1970) $\mathcal{F}$. infect. Dis., 122, 105

—, DAWSON, C. R., BaLAS, s., and Jones, P. (1970) Amer. F. Ophthal., 70, 375

SOWA, J., Collier, L. H., and SOWA, s. (197I) F. Hyg. (Camb.), 69, 693

THYGESON, P. (1946) Amer. F. Ophthal., 29, 1499

VASTiNe, D. W., DAWSON, C. R., DAGHFous, T., MESSADI, M., HOSHIWARA, I., YONEDA, C., and NATAF, R. (I974)

Brit. F. Ophthal., 58, 833

wilson, J. M. G., and Jungner, G. (1968) “Principles and Practice of Screening for Disease". Wld Hlth Org.

Publ. Hlth Papers No. 34. Geneva 